\title{
Stem Cell Research: The California Experience
}

\author{
Arlene Y. Chiu and Zach W. Hall \\ California Institute for Regenerative Medicine, San Francisco, California 94107
}

Rarely has a field of biomedical research caught the public imagination as dramatically as stem cell research. The idea of transplanting human cells that have been grown in vitro to replace damaged or diseased tissues and to restore function is easy to understand and is appealing in its concept. Moreover, cell replacement therapy has potentially wide application for scores of diseases ranging from diabetes to cancer to arthritis. Among these, disorders of the nervous system are particularly prominent, partly because many of them, such as brain and spinal cord injury and the neurodegenerative diseases, currently lack effective therapies. For other brain disorders, including mental illness, stem cells may be used as tools for diagnosis, for discovery about the cause of disease, and as a means to develop other therapies. Despite the scientific and medical excitement surrounding stem cell research, its development in the United States has been hampered by political roadblocks and ethical controversy. As neuroscientists currently involved in starting a major new funding agency for stem cell research in California, we have been fascinated by the scientific opportunities and the social and political challenges of this new enterprise. We discuss here both the potential of stem cell research for neurological and psychiatric disorders and our experience in starting a major, new, governmental funding agency for stem cell research.

\section{Benefits of stem cell research for brain disease}

The most obvious and familiar application of stem cell research for nervous system disorders is through cell replacement

Received May 10, 2006; revised; accepted May 10, 2006.

Correspondence should be addressed to Dr. Zach W. Hall, President and Chief Scientific Officer, at the above address. E-mail: zhall@cirm.ca.gov. DOI:10.1523/JNEUROSCI.2006-06.2006

Copyright $\odot 2006$ Society for Neuroscience $\quad$ 0270-6474/06/266661-03\$15.00/0 therapy. Because neurogenesis is rare in the adult CNS and neurons do not regenerate, their loss, whether by neurodegeneration or through injury, is essentially irreversible. The possibility of using stem cells as a source of neurons that can be implanted to replace cells and circuits lost in Parkinson's disease, amyotrophic lateral sclerosis (ALS), Huntington's disease, or Alzheimer's disease is an exciting prospect. This approach is likely to be most successful for diseases such as Parkinson's disease, in which a defined cell type is lost from a discrete locus in the brain where it can be replaced. Some studies in which Parkinson's patients received transplants of fetal tissue with neural progenitor cells have shown promise (Piccini et al., 2005). As a practical measure, however, the numbers and poorly defined quality of cells that can be obtained from fetal tissue limits their use; deriving well characterized neural progenitors in vitro from human embryonic stem cells is a possible solution to this problem.

Progenitors of glial cells are also being explored as treatments for complex conditions such as spinal cord injury. In one study, transplantation of astrocytes from glial precursors derived from fetal tissue appeared to limit the astrocytic scarring that restricts axonal regeneration after traumatic injury to the CNS (Davies et al., 2006). Other studies on rodent models of spinal cord injury have shown that oligodendryocyte precursors derived from human embryonic stem cells can remyelinate axons and improve recovery of function (Keirstead et al., 2005).

In addition to these two examples, cell replacement therapy may offer benefit for other diseases of the nervous system, including neurodegenerative diseases, multiple sclerosis, and even stroke. The potential benefit of stem cell research extends much farther, however. Stem cells and their differentiated progeny can serve as vehicles of delivery for growth factors, enzymes, and other cellular products to the nervous system. The leukodystrophies and Batten's disease are examples of diseases in which an enzymatic defect results in the accumulation of metabolites that damage neural cells during development. Glial progenitors may be ideal cellular vectors for restoration of the missing enzyme because of their ability to migrate throughout the developing nervous system. Delivery of growth factors to localized areas may also prove useful after stroke or other injury. As delivery vehicles, progenitors derived from embryonic stem cells have two advantages over other cell types (such as fibroblasts): (1) they can be expanded almost indefinitely and engineered to overexpress selected molecules; and (2) neural and glial progenitors seem to have the unusual property of homing to sites of injury in the CNS (Nakatomi et al., 2002; Lee et al., 2006).

Other ways in which stem cell research may contribute, directly or indirectly, to treatment of neurological disease include the following: a better understanding of early development; stimulation and management of endogenous neural stem cells; better understanding of the behavior of glioblastoma and other tumors of the nervous system; and the possible use of hematopoietic stem cells to treat autoimmune disease, including those that afflict the nervous system. One of the most important potential uses of stem cells, however, may arise from the possibility of creating new cell lines from embryos that carry genetic diseases: embryos from preimplantation genetic diagnosis in which the genetic defect is known, or embryos from somatic cell nuclear transfer, which can be used even when the genetic defect(s) is not known. Although many neurological and psychiatric disorders have 
inherited forms, the cellular mechanisms that cause these diseases are unknown. Such stem cell lines could be used to produce the neuronal or glial cell types known to be affected or afflicted in the disease (e.g., somatic motor neurons for ALS, substantia nigra neurons for Parkinson's disease, medium spiny neurons from the basal ganglia for Huntington's disease, and oligodendrocytes for multiple sclerosis). Such human cellular disease models could be powerful tools for investigating the pathophysiology of different populations of cells, for identifying new genetic targets for drug development, or even as substrates for screening for drugs that give phenotypic rescue.

\section{Stem cell research: the \\ California experience}

Despite the tremendous scientific and medical promise of human embryonic stem cell research, the federal government has limited progress in this field by its restrictive funding policies. On August 9, 2001, President George W. Bush ended several decades of federal ambivalence and indecision about stem cell research by announcing on a national television broadcast that, for the first time, federal funds could be used to support human embryonic stem cell research, but on a very limited basis. Only research on human embryonic stem cell lines derived before the presidential announcement would be eligible for federal funding. Today, 5 years later, there are only 38 unique lines that fulfill the President's criteria, and, as a practical matter, only a handful are available to most investigators. The narrowness of federal support has significantly hampered the ability of U.S. scientists to participate in developing this new field. In a classic understatement, Dr. James Battey, the Chair of the Stem Cell Task Force at the National Institutes of Health (NIH), noted that he could not see how having more stem cell lines could be detrimental to science. Even Dr. Elias Zerhouni, the Director of the $\mathrm{NIH}$, stated to a Senate Appropriations Subcommittee that "from a purely scientific standpoint, more stem cell lines may well be helpful."

In response to the federal limitation, a number of states, including Ohio, New Jersey, Connecticut, and Illinois, have taken steps to fill the funding gap. Chief among these is California, where voters in November 2004 approved, by a vote of $59 \%$, to spend $\$ 3$ billion to fund stem cell research at California institutions over a 10 year period. The ballot measure, known as Proposition 71, provided for the establishment of a new state agency, the California Institute of Regenerative Medicine (CIRM), to administer the funds, under the guidance of a 29-member board, the Independent Citizens Oversight Committee (ICOC), composed of scientists from leading nonprofit biomedical research institutions, patient advocates, and representatives from the private sector. The proposition also established several working groups, whose members are chosen by the ICOC, to aid the Institute in its work. The Grants Working Group, composed of scientists from outside California as well as patient advocates, reviews grant applications and makes recommendations for funding to the ICOC; the Facilities Working Group, composed of real estate experts and patient advocates, serves a similar function for facilities grants (the proposition allows up to $10 \%$ of the funds to be spent for facilities); and the Standards Working Group, composed of ethicists, basic and clinical scientists, and patient advocates, establishes medical and ethical standards.

During its first year, CIRM has faced formidable obstacles. Most seriously, opponents of stem cell research filed suit against the Institute in May 2005 asserting, among other charges, that CIRM was unconstitutional, because it was under inadequate state control and thus could not issue bonds backed by the state. This and a number of other claims brought by the litigants were soundly rejected by a decision in Alameda County Superior Court on April 21, 2006. The litigants have announced that they intend to appeal the decision all the way to the State Supreme Court, which could take as much as another year.

The unfortunate result is that the Institute is unable to raise bond money for grants in the commercial markets as long as its constitutionality is under legal challenge. In response, the Institute is operating on donations and is borrowing money from philanthropic foundations and individuals to begin funding grants. We have successfully raised over $\$ 12$ million to fund the first year of a training grant program in stem cell research that will support 170 trainees at 16 institutions across California and are seeking $\$ 36$ million more to fund a round of research grants. We are also seeking gifts to support the scientific activities of the Institute. Plans are underway for a scientific meeting on the "Assessment of Medical Risk to Egg Donors," which will be organized by the Institute of Medicine and the National Research Council of the National Academies, and for a joint meeting with the Medical Research Council of the United Kingdom, where 16 scientists from California and 16 from the United Kingdom will focus on stem cell self-renewal and differentiation. Both meetings are planned for the fall of 2006.

A major accomplishment during the year has been to establish the policies by which CIRM-funded research will be done. The Medical and Ethical Standards Working Group has developed standards that have been approved by our board and are in the process of becoming state regulations. When enacted, these standards, which are based on the Guidelines for $\mathrm{Hu}$ man Embryonic Stem Cell Research developed by the National Academies (http:// www.nap.edu/books/0309096537/html), will be the most comprehensive set of regulations on stem cell research in the country. We hope these regulations will set a standard for other states to follow as they develop their own programs. The ICOC has also approved an Intellectual Property Policy for Non-Profit Institutions and a comprehensive Grants Administration Policy for Academic and Non-Profit Institutions.

Finally, we are engaged in developing a scientific strategic plan that will guide our funding activities over the coming years. Our first step was a scientific conference, "Stem Cell Research: Charting New Directions for California," held last year in which we invited scientists from all over the world to help us identify major challenges and opportunities in stem cell research. We will incorporate these and other suggestions into a broad and comprehensive plan for stem cell research. Our aim is to be ready to move quickly once the litigation is ended and the full stream of public money is available to us. The voters of California have charged us with developing stem cell research for therapies, and there is no time to waste.

Despite the lack of funding, Proposition 71 has provided an important stimulus for stem cell research in California and in other states. In California, universities and other research institutions have hired new faculty, raised private capital, and planned new buildings for stem cell research so that they will be ready to compete for public funds once they are available. Faced with competition from California, other states have committed funds, and, in some cases, private founda- 
tions have been started to support local stem cell research. As new efforts are mounted in various states across the country, it will be important to ensure mechanisms for collaboration and for transparency, so that new stem cell lines that are derived can be widely shared. The net effect of all of this activity is that despite political and ethical controversy, stem cell research in the United States has taken on new life, driven in part by the California experiment.

\section{References}

Davies JE, Huang C, Proschel C, Noble M, MayerProschel M, Davies SJ (2006) Astrocytes derived from glial-restricted precursors promote spinal cord repair. J Biol 5:7.

Keirstead HS, Nistor G, Bernal G, Totoiu M, Cloutier F, Sharp K, Steward O (2005) Human embryonic stem cell-derived oligodendrocyte progenitor cell transplants remyelinate and restore locomotion after spinal cord injury. J Neurosci 25:4694-4705.

Lee SR, Kim HY, Rogowska J, Zhao BQ, Bhide P, Parent JM, Lo EH (2006) Involvement of matrix metalloproteinase in neuroblast cell migration from the subventricular zone after stroke. J Neurosci 26:3491-3495.

Nakatomi H, Kuriu T, Okabe S, Yamamoto S, Hatano O, Kawahara N, Tamura A, Kirino T, Nakafuku M (2002) Regeneration of hippocampal pyramidal neurons after ischemic brain injury by recruitment of endogenous neural progenitors. Cell 110:429-441.

Piccini P, Pavese N, Hagell P, Reimer J, Bjorklund A, Oertel WH, Quinn NP, Brooks DJ, Lindvall O (2005) Factors affecting the clinical outcome after neural transplantation in Parkinson's disease. Brain 128:2977-2986. 